Brazilian Journal

of Chemical

ISSN 0104-6632

Engineering

\title{
ADSORPTION OF ACID BLUE 1 ON ACTIVATED CARBON PRODUCED FROM THE WOOD OF Ailanthus altissima
}

\author{
F. K. Bangash ${ }^{1 *}$ and S. Alam ${ }^{2}$ \\ ${ }^{1}$ Institute of Chemical Sciences, University of Peshawar, \\ Phone/Fax: +(92) (91) 9216652, Peshawar, 21250, Pakistan. \\ E-mail: fazlullah52@yahoo.com \\ ${ }^{2}$ Department of Chemistry, University of Malakand, at Chakdara, Dir (L), \\ NWFP, Pakistan. \\ E-mail: sultangsh@yahoo.com
}

(Submitted: November 6, 2006 ; Revised: January, 82009 ; Accepted: January 9, 2009)

\begin{abstract}
Carbon prepared from the wood of Ailanthus altissima, at 400 and $800^{\circ} \mathrm{C}$ was used to adsorb acid blue 1 from aqueous solution at $10^{\circ} \mathrm{C}$ and $45^{\circ} \mathrm{C}$. Characterization by XRD, SEM, EDS and FTIR shows that the surfaces contain functional groups like carboxyl which disappear at $800{ }^{\circ} \mathrm{C}$ and thus favor the exposure of more porous structural surfaces which enhance the adsorption capacity. Relatively high amounts of carbon with respect to oxygen were found with the increase in activation temperature. First order, Bangham and parabolic models were found to fit the adsorption kinetic data. The reaction rate increased with the increase in temperature of adsorption/activation. Thermodynamic parameters like $\Delta \mathrm{E}^{\neq}, \Delta \mathrm{H}^{\neq}, \Delta \mathrm{S}^{\neq}$and $\Delta \mathrm{G}^{\neq}$were calculated. The negative values of $\Delta S^{\neq}$reflect the decrease in the disorder of the system at the solid-solution interface, during adsorption. Gibbs free energy $\left(\Delta G^{\neq}\right)$represents the driving force for the affinity of dye for the carbon and it decreased with the increase in adsorption/activation temperature.

Keywords: Activated carbon; Acid blue 1; Adsorption; Characterization.
\end{abstract}

\section{INTRODUCTION}

Color is a visible pollution. A slight coloration of a water source could make it unacceptable to consumers though it may not be toxic. The source of such pollution lies in the rapid increase in the use of synthetic dyes. More than 10,000 chemically different dyes are being manufactured, and the world dyestuff and dye intermediates production is estimated to be around $7 \times 10^{8} \mathrm{~kg}$ per annum (Vaidya et al., 1982). These are mainly consumed in textiles, tanneries, pharmaceuticals, food packing industries, pulp and paper, paint and electroplating industries. The effluents from dye manufacturing and dye application processes are highly colored. Other contaminants such as acids or alkalis, salts, dissolved and suspended solids and other toxic compounds may also be present in the effluents. Color in the receiving water bodies such as rivers or lakes can inhibit photosynthesis and its compounds can react with metal ions to form substances toxic to fish and other aquatic life (Karthikeyan, 1989). Technologies presently employed for color removal are based on physicochemical processes such as dilution, adsorption, coagulation and flocculation, chemical precipitation, oxidation, ion-exchange, reverse osmosis and ultra filtration (Banat et al., 1996). Several studies have been carried out in an effort to explore cheap and effective adsorbents for the removal of color from wastewaters. Amongst all the adsorbents, activated carbon is the most popular for the removal of pollutants from wastewater (Babel and Kurniawan, 2003; Derbyshire et al., 2001). In particular, the effectiveness of carbon for removal of a wide variety of dyes from wastewater has made it an ideal alternative to other expensive treatment

*To whom correspondence should be addressed 
options (Ramakrishna and Viraraghavan, 1997). The greater adsorption capacity of activated carbon is mainly due to its structural characteristics (porous texture), which give it a large surface area and a chemical nature that can be easily modified to increase their properties.

In the present study, activated carbon from a cheap biotic precursor was prepared, characterized and used for acid blue 1 adsorption with the objective to evaluate its potential for the removal of dye from aqueous solution.

\section{MATERIAL AND METHODS}

\section{Acid Blue 1}

The dye used was supplied by Sigma-Aldrich (Catalogue No. $=19,821$, dye contents $=50 \%$, formula weight $=566.68, \lambda_{\max } .635 \mathrm{~nm}$ ) and its chemical structure is shown in Figure 1.

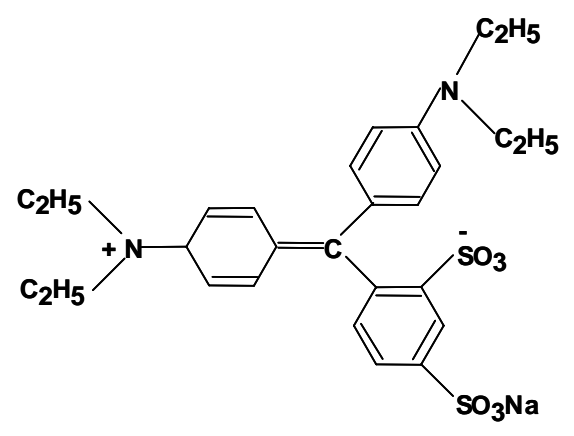

Figure 1: Chemical Structure of Acid blue 1

\section{Carbon Preparation}

The wood of Ailanthus altissima was air dried and then heated continuously for 5 hours on a flame burner in an iron container with a small outlet for the emission of volatile matter. Carbon obtained was allowed to cool in the container and then ground with the help of pestle and mortar and screened with US standards mesh 150-180 $\mu \mathrm{m}$. It was then treated with a $0.5 \mathrm{M}$ aqueous solution of $\mathrm{KOH}$ for 24 hours with occasional stirring. The mixture was then filtered and washed with double distilled water for the complete removal of basicity. The carbon was then leached with a $0.2 \mathrm{~N}$ solution of $\mathrm{HNO}_{3}: \mathrm{HCl}$ (1:1) and allowed to stand for 24 hours at room temperature with regular mixing. It was then filtered and washed with double distilled water until free from $\mathrm{Cl}^{-}$and $\mathrm{NO}_{3}{ }^{-}$ions. The carbon thus obtained was then air-dried in an oven at $105 \pm 1^{\circ} \mathrm{C}$. This treated carbon was then extracted with n-hexane for two hours in a soxhlet extractor and allowed to dry for 8 hours in a vacuum oven. The sample was then degassed by placing in silica $\left(\mathrm{SiO}_{2}\right)$ tubes, and heated at 400 and $800^{\circ} \mathrm{C}$ in a tube furnace (FS. 215 Gallenkamp England) with a vacuum facility. The carbon sample prepared was allowed to cool in a dessicator and then stored under nitrogen atmosphere.

\section{Characterization}

$\mathrm{pH}$ of the carbon sample suspension in $\mathrm{CO}_{2}$ free water (1:50) was determined by $\mathrm{pH}$ meter. The moisture content was measured by the weight loss of the sample on heating for two hours at $105 \pm 1{ }^{\circ} \mathrm{C}$ in an air dried oven. Ash content was obtained by ignition at $600^{\circ} \mathrm{C}$ in a Muffle furnace with the door partially open to provide a stream of air until the sample has been completely burned. The bulk density of the sample was also measured (Snell and Hilton, 1967).

BET- $\mathrm{N}_{2}$ adsorption experiments were carried out manometrically at $-196^{\circ} \mathrm{C}$ using the NOVA 2200 Quantachrome instrument. Surface area was obtained by applying the standard BET equation to the $\mathrm{N}_{2}$ adsorption data in the relative pressure range $\left(\mathrm{P} / \mathrm{P}_{\mathrm{o}}\right)$ 0.05 to 0.990 . The values of $0.81 \mathrm{~g} . \mathrm{cm}^{-3}$ and $16.2 \times$ $10^{-20} \mathrm{~m}^{2}$ were used for the density of liquid nitrogen at $-196^{\circ} \mathrm{C}$ and the molecular area of adsorbate nitrogen, respectively. The pore size distribution was determined by the DR method using NovaWin2 data analysis software of the instrument.

$\mathrm{X}$-rays diffraction (XRD) analysis of the sample was done with an X-ray diffractometer (RAD-1A, Rigaku Tokyo) using $\mathrm{Cu} \mathrm{K} \alpha$ radiation generated at $35 \mathrm{KV}, 20 \mathrm{~mA}$. The rectangular cavity of an aluminum sample holder was filled with the sample and scanned in a step-scan mode $\left(0.05^{\circ} /\right.$ step $)$ over the angular range of $7-30^{\circ}(2 \theta)$.

FTIR spectral analysis of the $\mathrm{KBr}$ (Spectrosol $\mathrm{BDH})$ mixed pellet of the sample was carried out with a FTIR spectrometer (Shimadzu 8201PC with FTCOM-1 computer control disc unit).

SEM (Model-JSM-5910, Japan JEOL) with EDS (INCA 200 Oxford Instruments) was used for the surface morphology and elemental analysis.

\section{Adsorption Kinetics}

$0.2 \mathrm{~g}$ of activated carbon and $20 \mathrm{~cm}^{3}$ of acid blue $1\left(2.0 \times 10^{-5} \mathrm{~mol} . \mathrm{dm}^{-3}\right)$ were taken up in a laboratory syringe (Hamilton CO.) and shaken for different intervals $\left(5-30\right.$ seconds) at 10 and $45^{\circ} \mathrm{C}$. The contents were filtered through $0.2 \mu$ filter paper fitted in the syringe-adapter. Residual concentration of the dye in the filtrate was determined with a uv-visible spectrophotometer. 


\section{RESULTS AND DISCUSSION}

\section{Characterization}

$\mathrm{pH}$, ash contents and bulk density and moisture contents was determined in the raw carbon and activated carbon $\left(400^{\circ} \mathrm{C}\right.$ and $\left.800^{\circ} \mathrm{C}\right)$ and the values are given in Table 1 .

BET, the most widely used method for the surface area $\left(\mathrm{m}^{2} \cdot \mathrm{g}^{-1}\right)$ measurements, make uses of the equation (Brunauer et al., 1938):

$\frac{1}{W\left(\frac{P_{\circ}}{p}-1\right)}=\frac{1}{W_{m} C}+\frac{C-1}{W_{m} C}\left(\frac{\mathrm{P}}{P_{\circ}}\right)$

where $W$ is the weight of gas adsorbed at a relative pressure $P / P_{o}$ and $W_{m}$ is the weight of adsorbate constituting a monolayer coverage. The term $C$ is the BET constant, and its value gives the energy of adsorption in the first adsorbed layer, indicating the magnitude of the adsorbent-adsorbate interactions. The $W_{m}$ can be obtained from the slope and intercept of the BET plot. From equation (1):

$$
\begin{aligned}
& \mathrm{S}=\frac{\mathrm{C}-1}{\mathrm{~W}_{\mathrm{m}} \mathrm{C}} \\
& \mathrm{i}=\frac{1}{\mathrm{~W}_{\mathrm{m}} \mathrm{C}}
\end{aligned}
$$

Thus, the weight of a monolayer $\left(\mathrm{W}_{\mathrm{m}}\right)$ can be obtained by combining equations (1a) and (1b).

$\mathrm{W}_{\mathrm{m}}=\frac{1}{\mathrm{~S}+\mathrm{i}}$

The total surface area $\left(S_{t}\right)$ of the sample can be expressed as:

$\mathrm{S}_{\mathrm{t}}=\frac{\mathrm{W}_{\mathrm{m}} \mathrm{NA}_{\mathrm{CS}}}{\mathrm{M}}$

Where $N$ is Avogadro's number $\left(6.023 \times 10^{23}\right)$ and $M$ is the molecular weight of the adsorbate and $A_{C S}$ is the cross sectional area of nitrogen gas (16.2 $\AA^{2} / \mathrm{mol}$ ). The BET surface area of the samples were obtained from the plots of $1 /\left[\mathrm{W}\left(\mathrm{P}_{\mathrm{o}} / \mathrm{P}\right)-1\right]$ vs. $\mathrm{P} / \mathrm{P}_{\mathrm{o}}$ of the $\mathrm{N}_{2}$ adsorption (Figure 2), which show that the Raw carbon, $400^{\circ} \mathrm{C}$ and $800^{\circ} \mathrm{C}$ activated carbon samples have values of $74.153,337.16$ and 387.28 $\mathrm{m}^{2} \mathrm{~g}^{-1}$ respectively. Type-I isotherms were obtained (Figure 3). Such types of isotherms are concave to the $\mathrm{P} / \mathrm{P}_{\mathrm{o}}$ axis and $\mathrm{N}_{2}$ uptake is governed by accessible micropore volume rather than the internal surface area. Such a behavior indicates the presence of mainly microporous structures. The pore volumes of the Raw carbon, $400^{\circ} \mathrm{C}$ and $800^{\circ} \mathrm{C}$ activated carbon were $0.020,0.110$ and $0.120 \mathrm{~cm}^{3} \cdot \mathrm{g}^{-1}$, respectively. The increase in surface area and pore volume with increase in activation temperature is due to the driving off of the tar in gaseous form that was trapped in the porous structure (Hassler 1974).

Table 1: Physical parameters of carbon.

\begin{tabular}{|l|c|r|r|}
\hline \multirow{2}{*}{ Physical Parameter } & \multirow{2}{*}{ Raw carbon } & \multicolumn{2}{|c|}{ Activated carbon } \\
\cline { 3 - 4 } & & $\mathbf{4 0 0}^{\mathbf{0}} \mathbf{C}$ & $\mathbf{8 0 0}^{\mathbf{0}} \mathbf{C}$ \\
\hline $\mathrm{pH}$ & 8.950 & 8.850 & 9.990 \\
Ash Content & 6.30 & 5.020 & 3.000 \\
Bulk Density $\left(\mathrm{kg} / \mathrm{m}^{3}\right)$ & 210 & 195 & 165 \\
Moisture content \% & 1.50 & 0.600 & 0.4200 \\
\hline
\end{tabular}

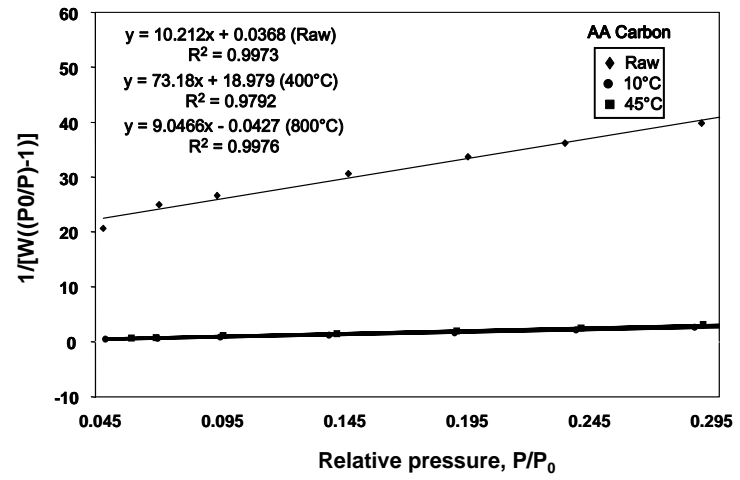

Figure 2: BET plots of nitrogen adsorption on carbon

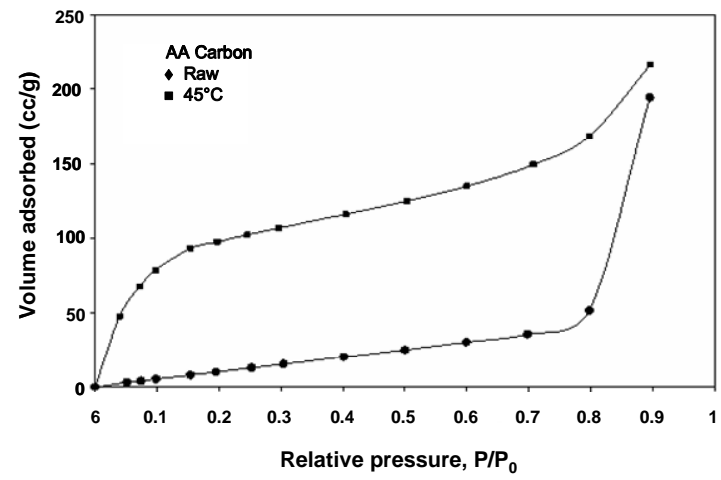

Figure 3: Nitrogen adsorption isotherms on carbon samples 
FTIR spectral bands (Figure 4 - 6) in the region of $2779.2 \mathrm{~cm}^{-1}, 2854.5 \mathrm{~cm}^{-1}$ and $2588.3 \mathrm{~cm}^{-1}$ are present only in the Raw and $400^{\circ} \mathrm{C}$ samples but are absent in the $800^{\circ} \mathrm{C}$ sample. The bands are ascribed to aliphatic $-\mathrm{CH}_{3},-\mathrm{CH}_{2}$ and $-\mathrm{CH}$ stretching. The peak at $2300 \mathrm{~cm}^{-1}$ is due to the presence of ketones (Cooke et al., 1986). A weak absorption band in Raw and $400^{\circ} \mathrm{C}$ at $1719 \mathrm{~cm}^{-1}$ represents $\mathrm{C}=\mathrm{O}$ stretching, indicating the presence of various oxygen groups such as carboxyls (Bhabendra et al., 1999). The bands in the region $1000-1100 \mathrm{~cm}^{-1}$ confirm the presence of mineral matter (Ahmad et al., 2004), and between $900-700 \mathrm{~cm}^{-1}$ are aromatic bands for substituted benzene rings (Cooke et al., 1986).

Scanning electron micrographs of the carbon samples (Figure 7) have hexagonal pores. The EDS, which gives semi quantitative analysis, shows that, with the increase in activation temperature, the carbon content of the samples has increased, $83.48 \%$ (Raw), $86.89 \%\left(400^{\circ} \mathrm{C}\right), 91.57 \%\left(800^{\circ} \mathrm{C}\right)$, but has decreased the oxygen content, $16.18 \%$ (Raw), $12.21\left(400^{\circ} \mathrm{C}\right), \quad 7.13 \quad\left(800^{\circ} \mathrm{C}\right) . \quad$ Elements like magnesium, potassium, calcium, chlorine, iron and copper were found in trace quantities.

The X-ray diffraction patterns (Figure 8 - 10) of carbon samples have a peak corresponding to $2 \theta \approx$ $22^{\circ}$ which shows the disordered graphitic 002 planes (Bhabendra et al., 1999). The Raw carbon showed the presence of a phase like molybdenum sulfide chloride- $\mathrm{Mo}\left(\mathrm{S}_{2}\right)_{3} \mathrm{SCl}_{4}[$ file number 74-2043], that of $400^{\circ} \mathrm{C}$ had the phase of chromium carbonyl cobalt tungsten phosphide- $(\mathrm{CO})_{5} \mathrm{Cr}(\mathrm{CO})_{5} \mathrm{WP}_{2} \mathrm{CO}_{2}(\mathrm{CO})_{6}$ [file number 77-2229] and the $800^{\circ} \mathrm{C}$ degassed carbon showed the phase of 2, 4-dinitromesitylene$\mathrm{C}_{9} \mathrm{H}_{10} \mathrm{~N}_{2} \mathrm{O}_{4}$ [file number 13-0780]. It has been reported ( $\mathrm{Lu}$ et al., 2001) that activated carbon has an intermediate structure between graphite and amorphous state, the so-called turbostratic structure or random layer lattice structure. Unlike graphite, carbonaceous material crystallite is extremely small and contains some aliphatic side chains on its edges. These small crystallites can be linked via their chains to form the so-called macromolecules, with the amorphous carbon being trapped in it.

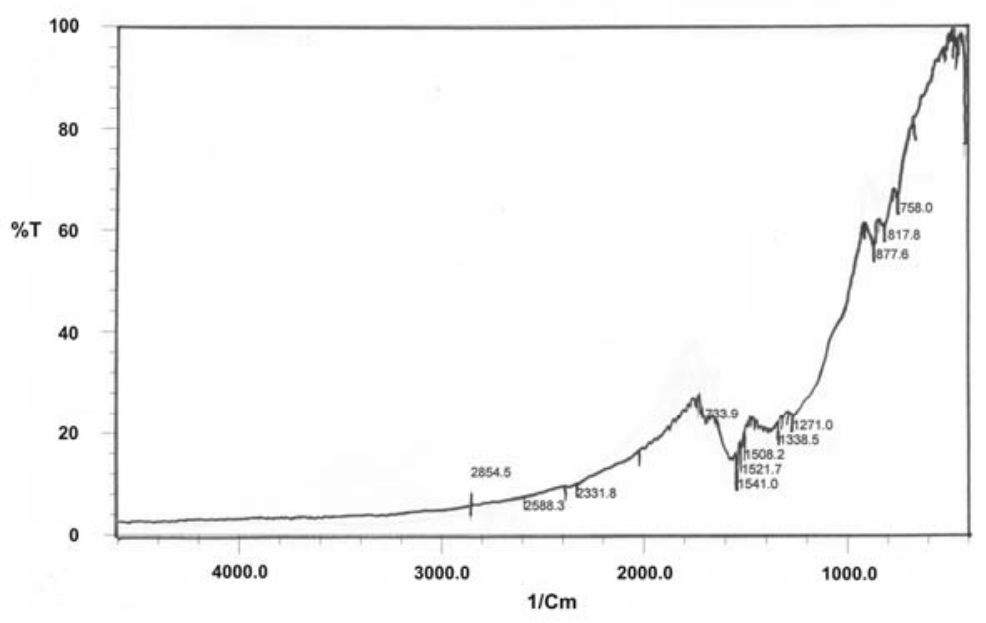

Figure 4: FTIR spectrum of raw carbon

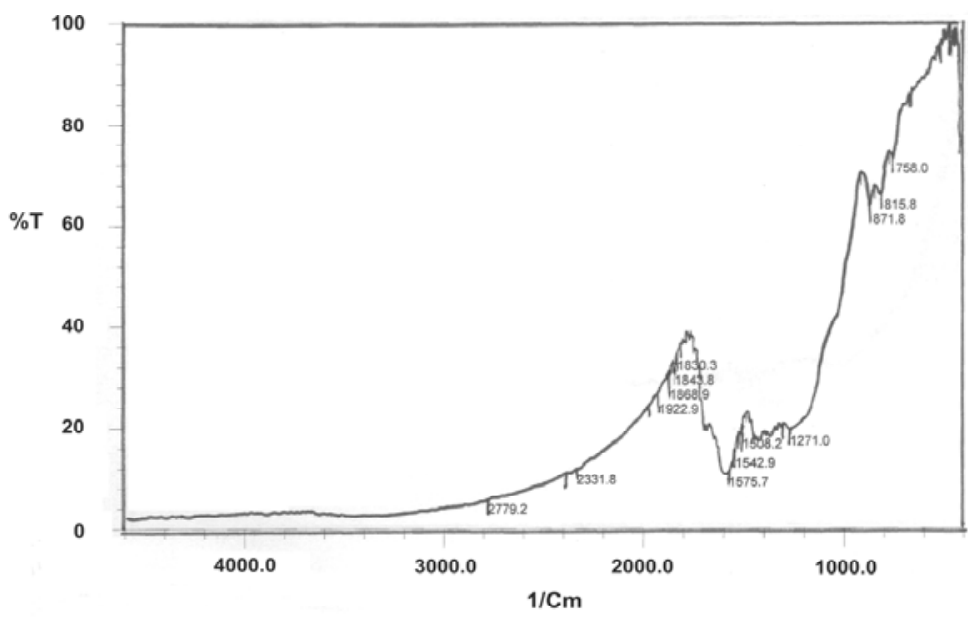

Figure 5: FTIR spectrum of $400^{\circ} \mathrm{C}$ activated carbon 


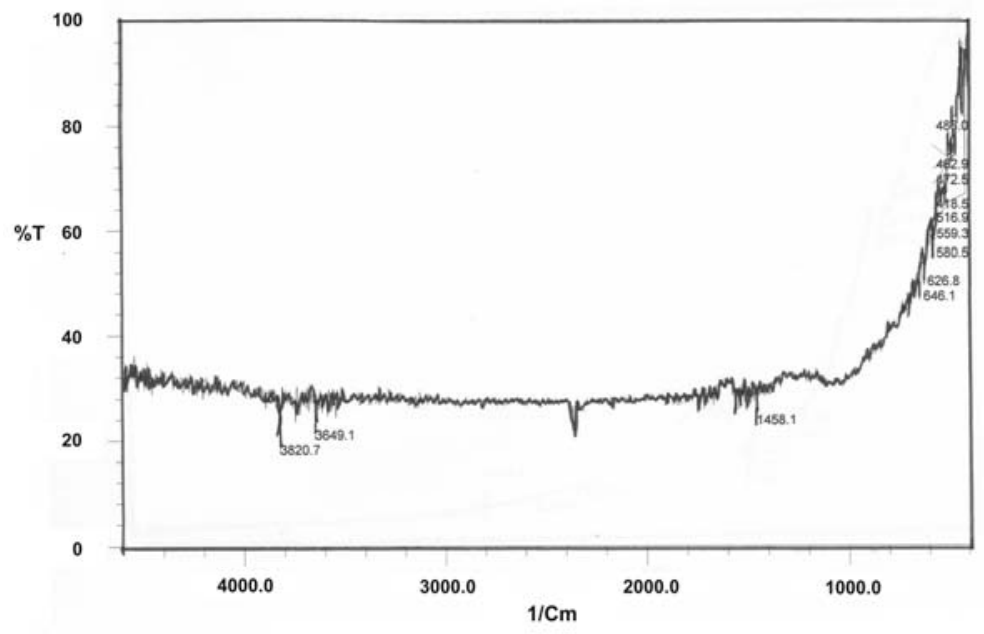

Figure 6: FTIR spectrum of $800^{\circ} \mathrm{C}$ activated carbon

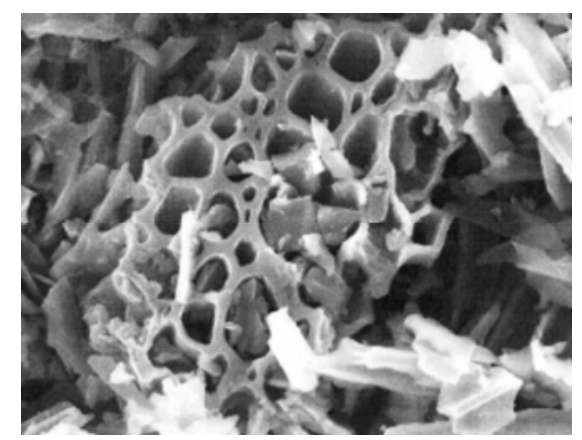

a) Raw carbon (Mag. 1000x, -20 $\mu \mathrm{m}$ )

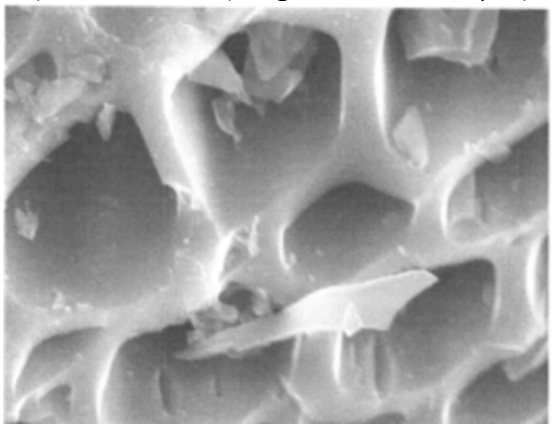

c) $400^{\circ} \mathrm{C}$ activated carbon (Mag. $\left.3500 \mathrm{x},-5.7 \mu \mathrm{m}\right)$

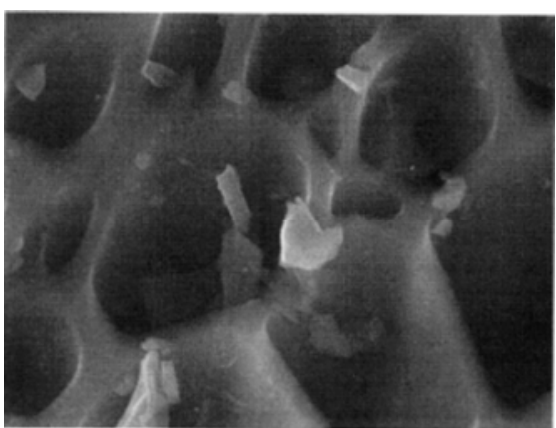

b) $400^{\circ} \mathrm{C}$ activated carbon (Mag. $3500 \mathrm{x},-5.7 \mu \mathrm{m}$ )

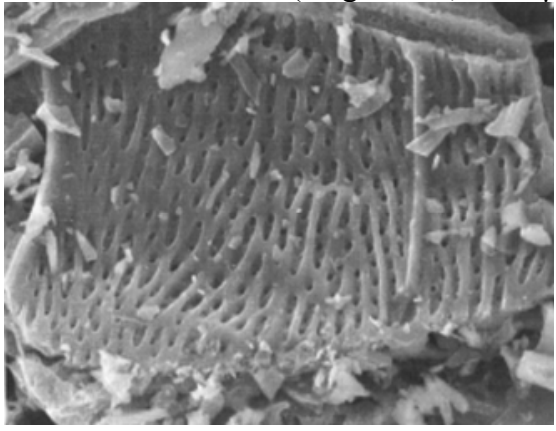

d) $800^{\circ} \mathrm{C}$ activated carbon (Mag. $\left.1000 \mathrm{x},-20 \mu \mathrm{m}\right)$

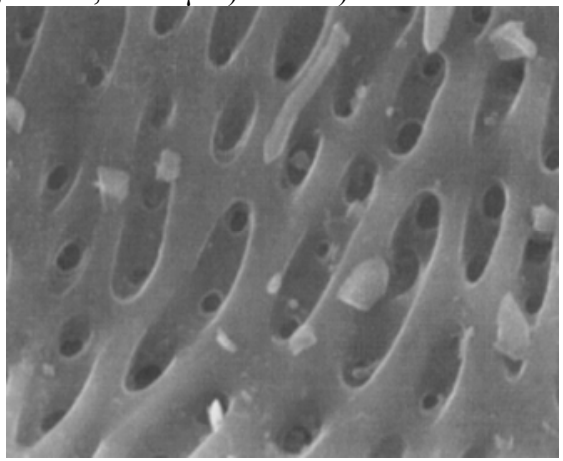

e) $800^{\circ} \mathrm{C}$ activated carbon (Mag.3500x, $-5.7 \mu \mathrm{m}$ )

Figure 7: $(\mathrm{a}-\mathrm{d})$ : Scanning electron micrographs of carbon $(\mathrm{AccV}=20 \mathrm{kV}$, Signal $=$ SEI, WD $=16 \mathrm{~mm}$, Spot Size $=25)$ 


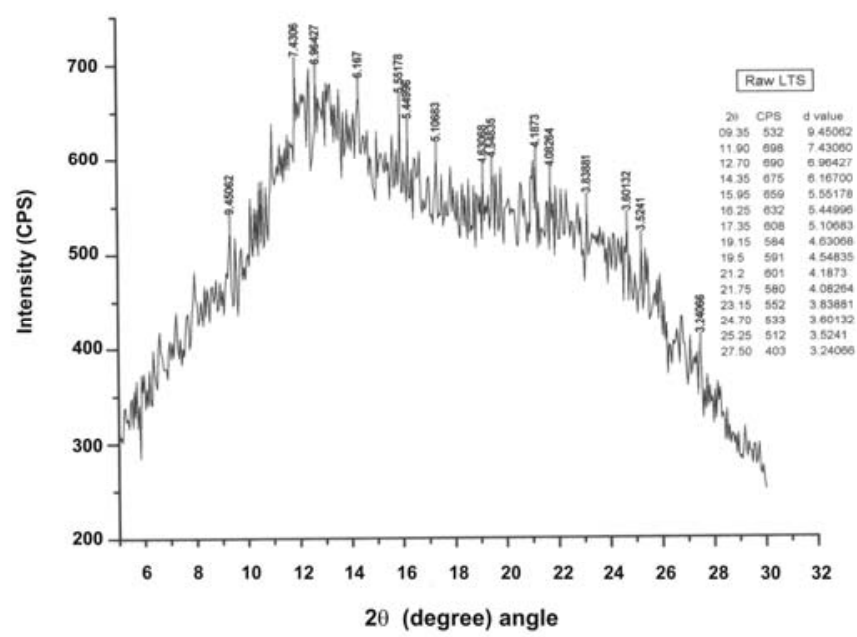

Figure 8: XRD spectrum of Raw carbon.

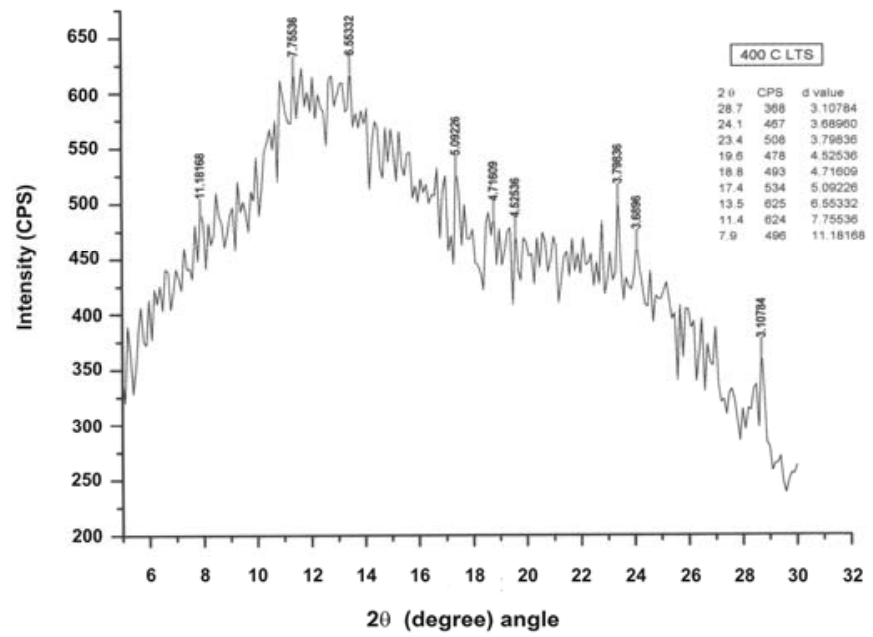

Figure 9: $\mathrm{XRD}$ spectrum of $400^{\circ} \mathrm{C}$ activated carbon.

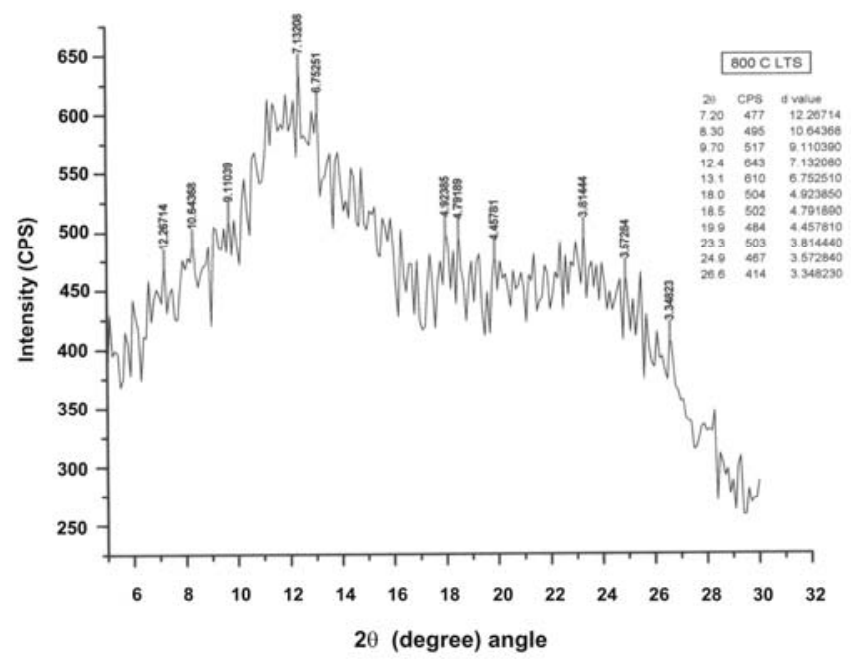

Figure 10: XRD spectrum of $800^{\circ} \mathrm{C}$ activated carbon. 
Effect of Functional Groups on Adsorption

Acid blue 1 is an anionic triphenylmethane dye carrying a sulfonic acid group. In aqueous solution, it ionizes to an anionic $\mathrm{SO}_{3}^{-}$group. The dye ion, on approaching to the surface, suffers Columbic repulsion with oxygen-containing functional groups (carboxyls, carbonyl etc.) present on the Raw and $400^{\circ} \mathrm{C}$ degassed carbon samples (Figures 4, 5). Adsorption of the dye on $800^{\circ} \mathrm{C}$ activated carbon is high due to the decrease in polarity of the carbon surface and decomposition of some of the acidic oxygen surface functionalities at this temperature. Some increase in adsorption might also have occurred due to an increase in the surface area by activation at high temperature due to opening of the blind pores, resulting in the increase in surface area and pore volume. A non-polar surface of the $800^{\circ} \mathrm{C}$ activated carbon sample is thus also a reason for the high adsorption of the dye. Lower adsorption of dye on the Raw and $400^{\circ} \mathrm{C}$ activated carbon samples may be

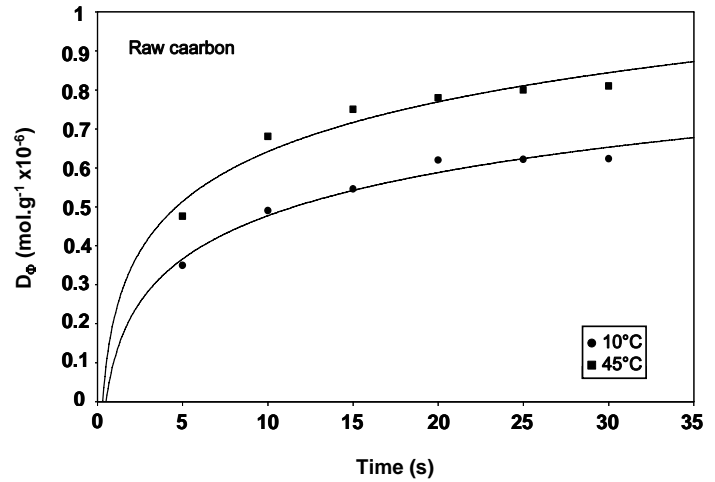

(a) due to the fact that polar functional groups situated at the pore opening adsorb water strongly through hydrogen bonds that in turn result in pore constriction or pore blockage.

\section{Kinetic Models}

The rate of adsorption of dye $\left(2 \times 10^{-5} \mathrm{~mol} . \mathrm{dm}^{-3}\right)$ at $10^{\circ} \mathrm{C}$ and $45^{\circ} \mathrm{C}$ (Figure 11a-c) is high in the initial fifteen seconds and then it becomes slow due to the possible diffusion into the micropores. Linear forms of the kinetic equations were applied to the data and their goodness of fit was estimated from the correlation coefficient $\left(r^{2}\right)$, standard error estimate $(\mathrm{SE})$, variance ratio $(\mathrm{F})$ and the level of significance of $\mathrm{F}$ statistic (P), (Table 2). Based on these parameters, it appears that the dye adsorption kinetics on the prepared carbon samples can be described reasonably well by the first order, Bangham and the parabolic diffusion models.

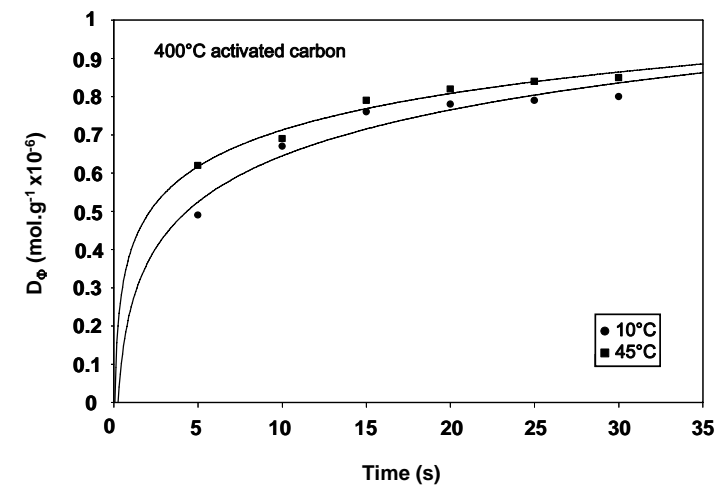

(b)

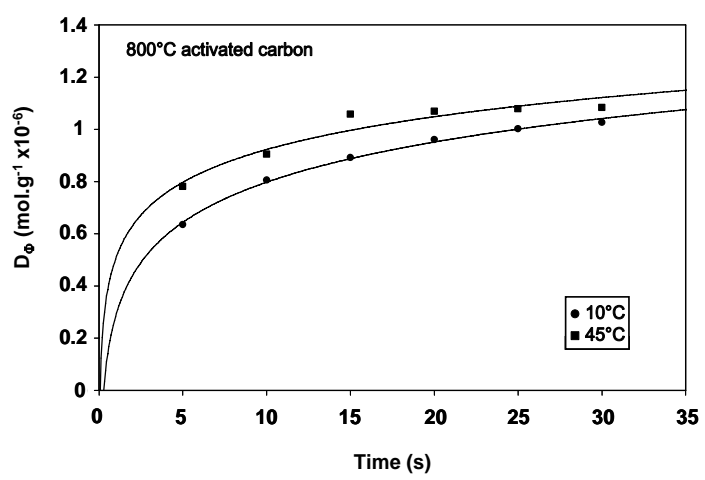

(c)

Figure 11: Adsorption kinetics of acid blue 1 on carbon. a) Raw carbon; b) $400^{\circ} \mathrm{C}$ activated carbon; c) $800^{\circ} \mathrm{C}$ activated carbon. 
Table 2: Values of SE, F statistics and $P$ for models fitted on kinetics adsorption of acid blue 1 on carbon.

\begin{tabular}{|c|c|c|c|c|c|c|c|}
\hline \multirow{2}{*}{ Carbon } & \multirow{2}{*}{ Mean Values } & \multicolumn{2}{|c|}{ First Order } & \multicolumn{2}{|c|}{ Bangham } & \multicolumn{2}{c|}{ Parabolic Function } \\
\cline { 3 - 8 } & & $\mathbf{1 0}^{\mathbf{0}} \mathbf{C}$ & $\mathbf{4 5}^{\mathbf{0}} \mathbf{C}$ & $\mathbf{1 0}^{\mathbf{0}} \mathbf{C}$ & $\mathbf{4 5}^{\mathbf{0}} \mathbf{C}$ & $\mathbf{1 0}^{\mathbf{0}} \mathbf{C}$ & $\mathbf{4 5}^{\mathbf{0}} \mathbf{C}$ \\
\hline \multirow{3}{*}{ Raw } & $\mathrm{SE}\left(\times 10^{-8}\right)$ & 4.356 & 8.71 & 2.81 & 3.06 & 3.94 & 5.38 \\
& $\mathrm{~F}\left(\times 10^{-8}\right)$ & 0.52 & 0.95 & 0.98 & 0.75 & 11.7 & 1.60 \\
& $\mathrm{P}\left(\times 10^{-8}\right)$ & 0.433 & 0.787 & 0.82 & 0.63 & 0.98 & 1.33 \\
\hline \multirow{3}{*}{$400^{\circ} \mathrm{C}$} & $\mathrm{SE}\left(\times 10^{-8}\right)$ & 12.31 & 14.7 & 2.95 & 1.09 & 3.51 & 2.92 \\
& $\mathrm{~F}\left(\times 10^{-8}\right)$ & 0.55 & 0.65 & 0.68 & 0.31 & 0.84 & 0.87 \\
& $\mathrm{P}\left(\times 10^{-8}\right)$ & 0.457 & 0.541 & 0.57 & 0.26 & 0.70 & 0.72 \\
\hline \multirow{3}{*}{$800^{\circ} \mathrm{C}$} & $\mathrm{SE}\left(\times 10^{-8}\right)$ & 3.77 & 11.05 & 1.22 & 1.84 & 3.29 & 4.61 \\
& $\mathrm{~F}\left(\times 10^{-8}\right)$ & 1.617 & 5.48 & 0.61 & 0.34 & 2.17 & 2.47 \\
& $\mathrm{P}\left(\times 10^{-8}\right)$ & 1.35 & 4.57 & 0.506 & 0.28 & 1.81 & 2.06 \\
\hline
\end{tabular}

Table 3: Thermodynamic parameters for the adsorption of acid blue 1 on carbon, calculated from the first order adsorption kinetics.

\begin{tabular}{|c|c|c|c|c|c|c|}
\hline \multirow{3}{*}{$\begin{array}{c}\text { Thermodynamic } \\
\text { Parameters }\end{array}$} & \multicolumn{6}{|c|}{ Carbon Samples } \\
\hline & \multicolumn{2}{|c|}{ Raw } & \multicolumn{2}{|c|}{$400^{\circ} \mathrm{C}$} & \multicolumn{2}{|c|}{$800^{\circ} \mathrm{C}$} \\
\hline & $10^{\circ} \mathrm{C}$ & $45^{\circ} \mathrm{C}$ & $10^{\circ} \mathrm{C}$ & $45^{\circ} \mathrm{C}$ & $10^{\circ} \mathrm{C}$ & $45^{\circ} \mathrm{C}$ \\
\hline$\Delta \mathrm{H}^{\ddagger}\left(\mathrm{kJmol}^{-1}\right)$ & -1.567 & -1.858 & -2.0783 & -2.369 & -2.091 & -2.38 \\
\hline$\Delta \mathrm{S}^{\neq}\left(\mathrm{Jmol}^{-1} \mathrm{~K}^{-1}\right)$ & -291.2 & -290.0 & -285.61 & -293.14 & -287.9 & -288.1 \\
\hline$\Delta \mathrm{G}^{f}\left(\mathrm{kJmol}^{-1}\right)$ & 80.861 & 90.362 & 78.749 & 90.85 & 79.38 & 89.21 \\
\hline$k\left(\mathrm{~s}^{-1}\right)$ & 0.0070 & 0.0095 & 0.0071 & 0.0079 & 0.0131 & 0.0145 \\
\hline
\end{tabular}

The first order equation in the linear form can be expressed as (Laidler 1965).

$\ln \mathrm{D}_{\sigma}=\ln \mathrm{Do}_{\mathrm{o}} \mathrm{k} \mathrm{t}$

Values of the rate constant, $k$, increased with the increase in both the adsorption and activation temperatures (Table 3). Also the $r^{2}$ values for the first order model indicate good agreement. The energy of activation for the adsorption was calculated using the Arrhenius equation in the form:

$\ln \frac{\mathrm{k}_{2}}{\mathrm{k}_{1}}=\frac{\mathrm{E}_{\mathrm{a}}}{\mathrm{R}}\left[\frac{\mathrm{T}_{2}-\mathrm{T}_{1}}{\mathrm{~T}_{1} \mathrm{~T}_{2}}\right]$

Where $E_{a}$ is the activation energy, $k_{1}$ and $k_{2}$ are rate constants at $T_{1}$ and $T_{2}, R$ is the gas constant (8.314 $\left.J \cdot k^{-1} \cdot m o l^{-1}\right)$. The energies of activation for the adsorption on the Raw carbon and activated at 400

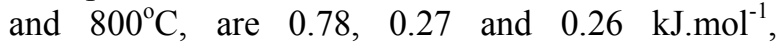
respectively, which shows that, with the increase in activation temperature, the activation energy of adsorption decreases. The high activation energy of adsorption on the Raw carbon and the $400^{\circ} \mathrm{C}$ degassed samples may be due to the presence of the polar functional groups at the pore opening, blocking the entrance of dye molecules and thus the energy barrier may arise from the repulsion. From the values of activation energies, other thermodynamic parameters such as Gibbs free energy of activation $(\Delta G)^{\neq}$, enthalpy of activation $(\Delta H)^{\neq}$and entropy of activation $(\triangle S)^{\neq}$were calculated (Table 3 ) by using the following equations (Laidler 1965).

$$
\begin{aligned}
& \Delta \mathrm{G}^{\#}=\Delta \mathrm{H}^{\#}-\mathrm{T} \Delta \mathrm{S}^{\#} \\
& \Delta \mathrm{H}^{\#}=\mathrm{Ea}-\mathrm{RT} \\
& \Delta \mathrm{S}^{\neq}=\mathrm{R}\left[\ln \frac{\mathrm{kh}}{\mathrm{k}_{\mathrm{B}} \mathrm{T}}+\frac{\Delta \mathrm{H}^{\neq}}{\mathrm{RT}}\right]
\end{aligned}
$$

Gibbs free energy $\left(\Delta G^{\ddagger}\right)$ represents the driving force for the affinity of dye for the carbon (Vickerstaff 1954). The negative values of the $\Delta G^{\neq}$ indicate spontaneity of the adsorption process. It was also noted that $\Delta G^{\ddagger}$ decreased with the increase in temperature, indicating high adsorption at higher temperatures. The enthalpy of activation $\left(\Delta H^{\ddagger}\right)$, calculated from the energy of activation, indicates that the process is endothermic in nature and decreased with increase in both the adsorption and the sample activation temperatures. The negative values of entropy of activation $\Delta S^{\ddagger}$ reflect affinity of the dye towards carbon and they also decreased with the increase in both the adsorption and activation temperatures, which indicates that the dye molecules have acquired a more stable orientation on the carbon surface (Table 3).

The Bangham equation in the linear form:

$\log \log \frac{\mathrm{D}_{\circ}}{\mathrm{D}_{\circ}-\mathrm{D}_{\sigma} \mathrm{W}}=\log \frac{\mathrm{kW}}{2.303 \mathrm{~V}}+\alpha \log \mathrm{t}$ 
was used to check the pore diffusion during the adsorption process (Aharoni, 1979). Linear plots were obtained (Figure 12a-c), by plotting $\log \left(D_{o} /\left(D_{o^{-}}\right.\right.$ $\left.D_{\sigma} W\right)$ ) vs. $\log t$. The values of $\alpha$ and $k$ calculated from the slopes and intercepts are given in Table 4. The decrease in $\alpha$ and increase in $k$ values of adsorption, with both the temperatures of adsorption and the sample activation, indicate the importance of the diffusion of dye into the pores of carbon and that adsorption into the pores is a diffusion controlled process, as was also reported by Qadeer et al., 1995.

The intraparticle diffusion was analyzed by applying the parabolic diffusion equation:

$\mathrm{D}_{\varphi}=\mathrm{B}+\mathrm{kt}^{1 / 2}$

to the data. For a solid-liquid adsorption process, the solute transfer is usually characterized by either external mass transfer (boundary layer diffusion) or intraparticle diffusion or both. The adsorption dynamics can be described by three consecutive steps, i.e., transport of the solute from bulk solution through liquid film to the adsorbent exterior surface; solute diffusion into the pores of adsorbent except for a small quantity of adsorption on the external surface; and the intraparticle transport mechanism of surface diffusion and adsorption of solute on the interior surfaces of the pores and capillary spaces of

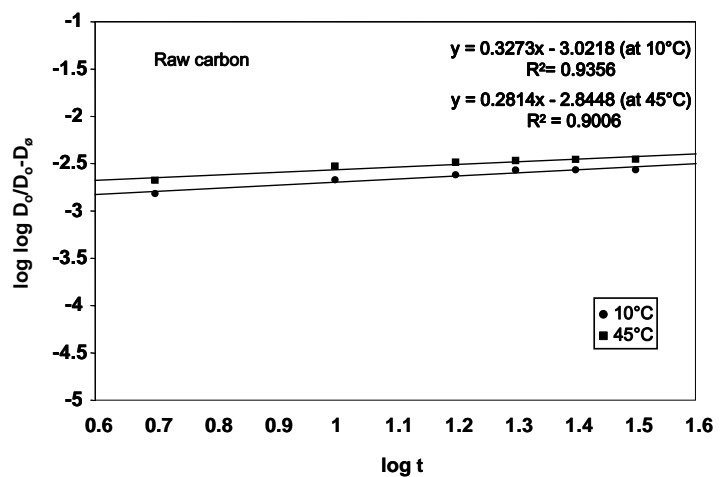

(a) the adsorbent. Of the three steps, the third step is assumed to be rapid and considered to be negligible. The overall rate of adsorption will be controlled by the slowest step, which would be either film diffusion or pore diffusion. However, the controlling step might be distributed between intraparticle and external transport mechanisms. In both cases, the external diffusion is involved in the adsorption process. The adsorption of dye onto carbon particles may be controlled by the film diffusion at earlier stages and then, as the adsorbent particles are loaded with dye ions, the adsorption process may then be controlled by the intraparticle diffusion. The $k$ value can be obtained from the slope of the plot $D_{\Phi}(\mathrm{mol} / \mathrm{g})$ vs. $t^{1 / 2}$. It can be seen from Figure 13a-c that the adsorption process has two phases. The linear portion ended with a smooth curve, followed by another linear portion. A similar type of trend has also been reported by Vadivelan (2005), Weber (1963), Weng 2006) and Kannan et al. (2001). The two phases in the intraparticle diffusion plot suggest that the adsorption process proceeds by surface adsorption followed by intraparticle diffusion. Calculated values of intraparticle diffusion coefficient, $k$, given in Table 4, increase with the increase in both the adsorption and sample activation temperatures. This is attributed to the instantaneous utilization of the most readily available adsorption sites on the carbon surfaces.

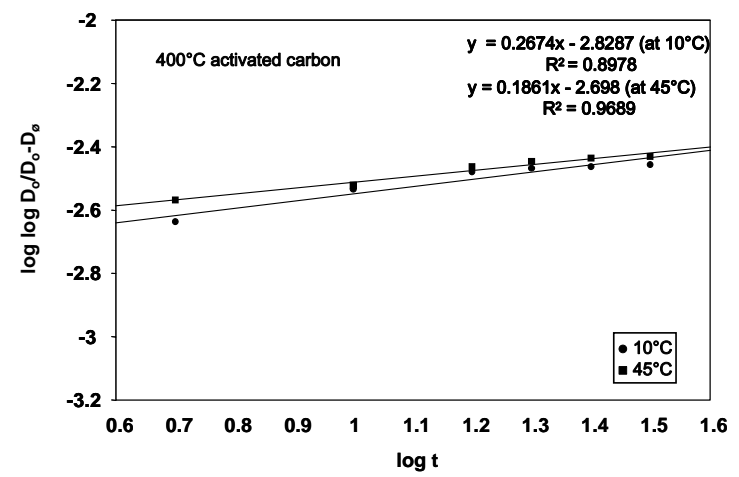

(b)

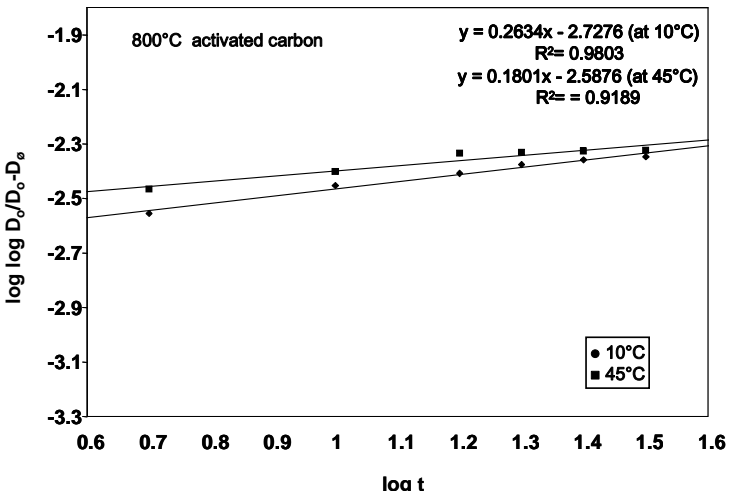

(c)

Figure 12: Bangham plots of the acid blue 1 adsorption on carbon. a) Raw carbon; b) $400^{\circ} \mathrm{C}$ activated carbon; c) $800^{\circ} \mathrm{C}$ activated carbon. 
Table 4: Kinetic rate constants of the Bangham and parabolic diffusion treatments of the adsorption of acid blue 1 on carbon.

\begin{tabular}{|c|c|c|c|c|c|c|c|c|}
\hline \multirow{3}{*}{ Carbon } & \multicolumn{4}{|c|}{ Bangham constants } & \multicolumn{4}{|c|}{ Parabolic constants } \\
\hline & \multicolumn{2}{|c|}{$\alpha$} & \multicolumn{2}{|c|}{$k$} & \multicolumn{2}{|c|}{ B } & \multicolumn{2}{|c|}{$k$} \\
\hline & $10^{\circ} \mathrm{C}$ & $45^{\circ} \mathrm{C}$ & $10^{\circ} \mathrm{C}$ & $45^{\circ} \mathrm{C}$ & $10^{\circ} \mathrm{C}$ & $45^{\circ} \mathrm{C}$ & $10^{\circ} \mathrm{C}$ & $45^{\circ} \mathrm{C}$ \\
\hline Raw & 0.3273 & 0.2814 & 0.2190 & 0.3292 & 0.0192 & 0.0220 & 0.3807 & 0.5319 \\
\hline $400^{\circ} \mathrm{C}$ & 0.2674 & 0.1861 & 0.3417 & 0.4616 & 0.0162 & 0.0167 & 0.5923 & 0.6282 \\
\hline $800^{\circ} \mathrm{C}$ & 0.2634 & 0.1801 & 0.4312 & 0.7540 & 0.0271 & 0.0285 & 0.6604 & 0.7824 \\
\hline
\end{tabular}

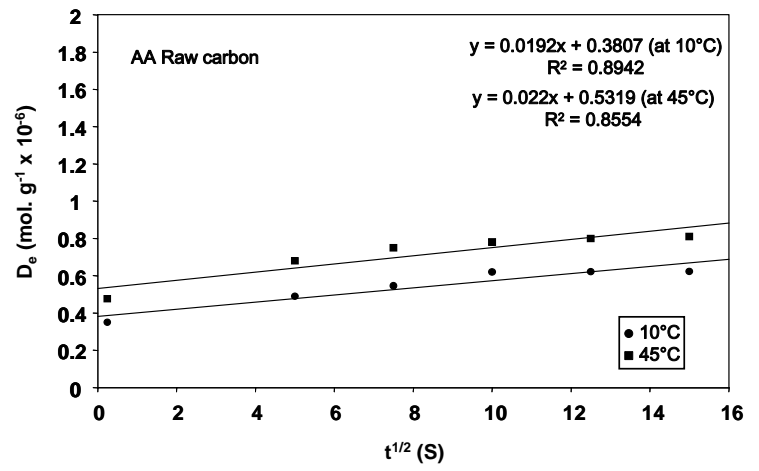

(a)

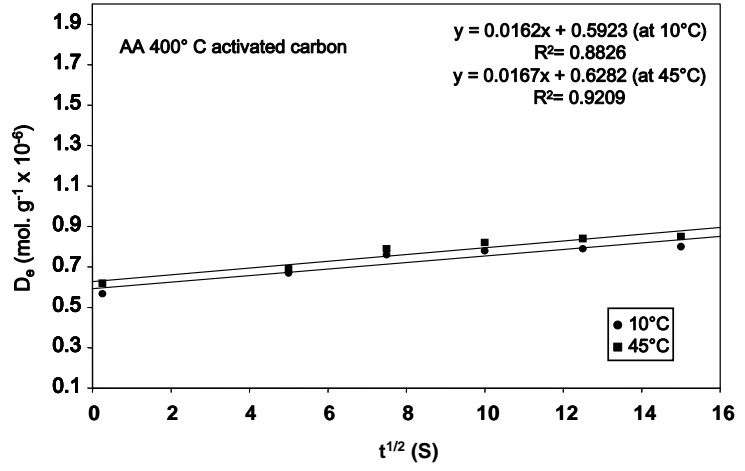

(b)

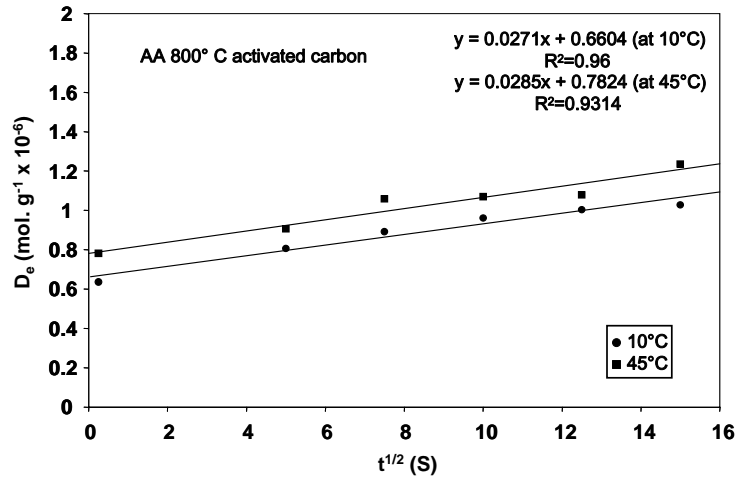

(c)

Figure 13: Parabolic diffusion plots of the acid blue 1 adsorption on carbon. a) Raw carbon; b) $400^{\circ} \mathrm{C}$ activated carbon; c) $800^{\circ} \mathrm{C}$ activated carbon.

\section{CONCLUSIONS}

Activated carbon, prepared from Ailanthus altissima, has surface functional groups like carboxyl groups, which disappear upon activation at $800^{\circ} \mathrm{C}$, thus improving the adsorption capacity. The EDS indicates the increased relative amount of carbon with respect to oxygen with the increase in activation temperature. Molecular adsorption and stable orientation was achieved in about 15 seconds. The first order, Bangham and parabolic equations were found to apply to the kinetic adsorption data. Both the intraparticle and pore diffusion processes were involved in the interaction of dye on the carbon surface. The carbon produced from the wood of Ailanthus altissima at $800{ }^{\circ} \mathrm{C}$ can be effectively used as adsorbent for the removal of acid blue 1 from aqueous solutions.

\section{ACKNOWLEDGEMENTS}

The authors thank the University of Peshawar for financial support. We thank the Centralized Resource Laboratory (CRL), University of Peshawar, for providing research facilities.

\section{NOMENCLATURE}

$B, \alpha \quad$ Constants

$D_{o} \quad$ Initial concentration of dye mol.dm ${ }^{-3}$ 


$\begin{array}{llr}D_{\sigma} & \begin{array}{l}\text { Solution concentration of } \\ \text { dye at time t }\end{array} \\ D_{\Phi} & \text { Amount adsorbed } & \mathrm{mol.g}^{-1} \\ F & \text { Variance ratio } & \\ \mathrm{h} & \text { Planck constant } & 6.626 \times 10^{-34} \\ k & \text { Rate constant } & \mathrm{Js} \\ \mathrm{k}_{\mathrm{B}} & \text { Boltzmann constant } & 1.3806 \times 10^{-23} \\ & & \mathrm{JK}^{-1} \\ P & \text { Significance of F statistics } & \\ S E & \text { Standard error estimate } & \mathrm{dm}^{-3} \\ V & \text { Volume of solution } & \mathrm{g} \\ W & \text { Weight of carbon }\end{array}$

\section{REFERENCES}

Aharoni, C., Sideman, S.; Hoffer, E. Adsorption of Phosphate Ions by Colloid Ion-Coated Alumina. J. Chem. Technol. Biotechnol., 29, $404-412$ (1979).

Ahmad, I., Khan, M. A., Ishaq, M., Shakirullah, M., Bahader, A., Spectral Characterization of Superficial Coal Group, J. Eng. and Appl. Sci., 23, 117-123 (2004).

Babel, S., Kurniawan, T. A., Low Cost Adsorbent for Heavy Metal Uptake from Contaminated Water: a Review, J. Hazardous Materials, B97, 219 - 243 (2003).

Banat, I., Nigam, P., Singh, D., and Marchant, R., Microbial Decolorization of Textile - Dye Containing Effluents: a Review, Bioresour, Technol., 58, 217-227 (1996).

Bhabendra, K., Pradhan., Sandle., N. K., Effect of Oxidizing Agents Treatments on the Surface Properties of Activated Carbon, Carbon, 32, 1231332 (1999).

Brunauer, S., Emmett, P., Teller, E. J., Adsorption of Gases in Multi-Molecular Layers, J. Am. Chem. Soc. 60, 309-319 (1938).

Cooke, N. E., Fuller, O. M., Gaikwad, R. P., FT-i.r. Spectroscopic Analysis of Coal and Coal Extracts, Fuel, 65, 1254-1259 (1986).

Derbyshire, F., Jagtoyen, M., Andrew, R., Rao, A., Martin-Gullon, I., Grulke, E., Carbon Materials in Environmental Applications, In: Radovic, L. R. (Ed.), Chemistry and Physics of Carbon, 27, Marcel Dekker, New York, 1 - 66 (2001).

Hassler, J. W., Purification with Activated Charcoal,
Chemical Publishing CO., INC. New York, 176 (1974)

Kannan, K., Sundaram, M. M. Kinetics and Mechanism of Removal of Methylene Blue by Adsorption on Various Carbons-a Comparative Study, Dyes Pig. 51, 25-40 (2001).

Karthikeyan, J., Removal of Color from Industrial Effluents. In: Trivedi, R. K. (Ed.), Pollution Management in Industries, Environmental Publication, Karad, India, 150 - 164 (1989).

Laidler, K. L., Chemical Kinetics, McGraw-Hill, New York, (1965).

Liu. Y. Some Consideration on the Langmuir Isotherm Equation, Colloids Surf. A: Physicochem. Eng. Aspects, 274, 34-36 (2006).

Lu. L., Shajwalla, V., Kong, C., Harris, D., Quantitative X-rays Analysis and its Applications to Various Coal, Carbon 39, 1821-1833 (2001).

Qadeer, R., Hanif, J., Saleem, M., Afzal, M., Kinetics and Thermodynamics of Some Metal Ions Adsorption on Activated Charcoal from Aqueous Solution, Jour. Chem. Soc. Pak., 17, 8286 (1995).

Ramakrishna, K. R., Viraraghavan, T., Dyes Removal Using Low Cost Adsorbent, Water Sci. Technol. 36, 189 - 196 (1997).

Snell, D. F., Hilton, C. L., Encyclopedia of Industrial Chemical Analysis, Intersc. Pub. New York, 4 (1967).

Sparks, D. L., Kinetics of Sorption/Release Reaction at the Soil Mineral/Water Interface, In: Spark, D.L (Ed.), Soil Physical Chemistry $2^{\text {nd }}$ ed. CRC Press, Boca Raton, FL, (1999).

Vadivelan, V., Kumar, K. V., Equilibrium, Kinetics, Mechanism and Process Design for the Sorption of Methylene Blue onto Rice Husk, J. Colloid Interf., Sci. 286, 90 - 100 (2005).

Vaidya, A. A, and Datye, K. V., Environmental Pollution during Chemical Processing of Synthetic Fiber, Colorate, 14, 3-10 (1982).

Vickerstaff, T. The Physical Chemistry of Dyeing, Intersc. Pub., New York, p. 100 (1954).

Weber Jr., W. J., Morris, J. C., Kinetics of Adsorption on Carbon from Solution. J. Sanit. Eng. Div. ASCE 89 (SA2), pp.31-59 (1963).

Weng, C., Pan. Y., Adsorption Characteristics of Methylene Blue from Aqueous Solution by Sludge Ash. Colloids Surf. A: Physicochem. Eng., 274, $154-162$ (2006). 